\title{
ORÇAMENTO NÃO PODE MAIS SER UMA PEÇA DE FICÇÃO
}

Coluna publicada em 2.6.2015: <http://www.conjur.com.br/2015-jun-02/ contas-vista-orcamento-nao-peca-ficcao $>$

A lei orçamentária já foi reconhecida no Brasil, em decisão do Supremo Tribunal Federal, como a mais importante depois da Constituição. ${ }^{1}$

No entanto, ato como o que ocorreu nos últimos dias, em que, em meio às medidas de ajuste fiscal, realizou-se um dos maiores - se não o maior - contingenciamento de que se tem notícia, ${ }^{2}$ indica que o orçamento não será cumprido tal como aprovado. Uma medida que, embora necessária para o equilíbrio das contas públicas, em nada colabora para dar seriedade e segurança jurídica a essa lei tão importante. Os contingenciamentos, tema sobre o qual já discorri especificamente em coluna anterior, ${ }^{3}$ e, como se pode ver, já se tornaram praxe na Administração Pública, estão cada vez mais intensos, distanciando o orçamento aprovado pelo Poder Legislativo daquele efetivamente cumprido pelo Poder Executivo, tornando excessiva a discricionariedade exercida ao longo da execução orçamentária e mitigando a credibilidade da lei orçamentária, que passa a se aproximar de uma "peça de ficção".

A lei orçamentária já foi muito criticada por ser essa "peça de ficção", verdadeira "formalidade" a ser cumprida pelos entes federados, para a qual não se davam atenção e respeito. Situação que não deixava de ser verdadeira até o início da década

1 "A lei orçamentária é a lei materialmente mais importante do ordenamento jurídico logo abaixo da Constituição", Min. Carlos Britto, p. 92 dos autos, STF, Tribunal Pleno, ADI 4.048 (Rel. Min. Gilmar Mendes, j. 14.5.2008).

2 Governo anuncia corte no Orçamento de quase 70 bilhōes, Valor Econômico, 22 de maio de 2015, dentre outras.

3 Hora é de "apertar o cinto" e contingenciar gastos, publicada em 11 de março de 2014. 
de 1990, em que estávamos sob um regime de alta inflação, sem moeda estável e confiável e de desorganização nas contas públicas. Mas que começou a se alterar a partir de 1994, com a estabilização da moeda, e se consolidou com a publicação da Lei de Responsabilidade Fiscal, em 2000. A estabilização da moeda e o aperfeiçoamento da legislação em matéria de finanças públicas mudaram esse quadro, e não há mais como reconhecer nem aceitar a lei orçamentária como uma peça de ficção.

No entanto, ainda há muito o que fazer para que a lei orçamentária passe a ocupar legitimamente o papel que lhe cabe, e foi corretamente reconhecido, de lei mais importante do ordenamento jurídico depois da Constituição.

Para que a lei orçamentária possa ter a eficácia e seriedade que justifiquem estar nesta posição de destaque, e sua elaboração torne-se o foro de discussão apropriado para as decisões sobre a adequada alocação dos recursos públicos, com a definição das políticas públicas, programas e ações governamentais que serão efetivamente realizados, e o Poder Legislativo torne-se o verdadeiro responsável por dar a palavra final, há alguns aperfeiçoamentos que se fazem necessários.

Em primeiro lugar, é preciso que apresente números confiáveis e representativos da realidade financeira do País, especialmente em termos de arrecadação, de modo a evitar que, logo após a publicação da lei orçamentária, já se reconheçam como inatingíveis os valores previstos, motivando contingenciamentos gigantescos como o que ora se apresenta. Algumas vezes de forma verdadeiramente despropositada, como o que ocorreu este ano com o orçamento federal, em que, ainda antes de ter sido aprovado, promoveu-se o contingenciamento fundado nas autorizaçóes provisórias da lei de diretrizes orçamentárias (LDO) que havia sido aprovada poucos dias antes - um só ato já foi capaz de pôr abaixo a credibilidade dos números apresentados não só no orçamento, mas também na LDO. ${ }^{4}$

$\mathrm{O}$ artigo 12 da Lei de Responsabilidade Fiscal é claro ao estabelecer que "as previsões de receita observarão as normas técnicas e legais, considerarão os efeitos das alterações na legislação, da variação do índice de preços, do crescimento econômico ou de qualquer outro fator relevante e serão acompanhadas de demonstrativo de sua evolução nos últimos três anos, da projeção para os dois seguintes àquele a que se referirem, e da metodologia de cálculo e premissas utilizadas". Um dispositivo legal que precisa ser efetivamente cumprido, pois sua estrita observância impede a apresentação de números pouco confiáveis, deixando para a execução orçamentária os ajustes que se tornarão cada vez mais indispensáveis ante os inevitáveis erros nas previsões.

4 Veja coluna $O$ direito financeiro precisa ser levado a sério, e 2015 começou mal, publicada em 10 de fevereiro de 2015. 
Previsões estas que, como determina a lei ora mencionada, devem ser feitas em observância a normas técnicas e legais, e não fundadas no "incrementalismo" vigente na maior parte dos entes federados, em que as previsões são feitas com base no orçamento executado no ano anterior, acrescido de algum valor a título de expectativas simplistas de provável aumento na arrecadação.

Por oportuno, abandonar a técnica do "orçamento incrementativo" é medida que se impõe para que as previsões da lei orçamentária sejam mais adequadas e próximas da realidade e evitem inúmeras outras distorçôes, inclusive na fase de execução orçamentária, como os indesejados gastos em final de exercício, ${ }^{5}$ inclusão exagerada de despesas em restos a pagar ${ }^{6}$ e a manutenção de programas que já não se mostram mais úteis e necessários. $\mathrm{O}$ orçamento precisa deixar de ter "caráter geológico", na bem-humorada expressão criada recentemente por Delfim Netto, mostrando que os programas "se acumulam em camadas" e nunca terminam. ${ }^{7}$

Necessário também que se dê efetivo e integral cumprimento ao art. $4^{\circ}$ da LRF, que confere à lei de diretrizes orçamentárias várias atribuições, destacando-se, entre outras também relevantes, a de regulamentar o já citado contingenciamento, estabelecendo "critérios e forma de limitação de empenho" (art. 4º I, b), o que evitaria seu uso impróprio, dando maior segurança e transparência a um instrumento por vezes necessário para ajustar eventuais imprecisōes ao longo da execução orçamentária que, se espera, sejam cada vez menores. Relevante também que a LDO estabeleça normas que regulamentem o controle de custos e avaliação dos resultados dos programas financiados com recursos dos orçamentos (art. $4^{\circ}, \mathrm{I}, e$ ), o que é fundamental para permitir a fiscalização, não só pelo sistema de controle já estabelecido constitucionalmente, mas também e principalmente pela sociedade, tornando transparente e factível a verificação de quanto custam e o que se espera da aplicação do dinheiro público tal como previsto na lei orçamentária.

É preciso também que se reconheça e se atribua efetivamente o caráter impositivo à lei orçamentária, abandonando a tese, que boa parte da doutrina já deixou de lado, de que o orçamento é lei meramente "formal", "autorizativa", sem caráter "mandatório" ou "impositivo", tornando facultativas suas disposiçóes. Entendimento

Veja coluna Natal é tempo de correr com a execução orçamentária, publicada em 11 de dezembro de 2012.

6 Veja coluna $O$ final do ano, as dividas e os restos a pagar, publicada em 17 de dezembro de 2013.

7 Antonio Delfim Netto, Por que não começar do começo de 2017? Valor Econômico, coluna publicada em 12 de maio de 2015. 
que não se coaduna com o atual sistema de planejamento governamental, em que as leis orçamentárias representam os principais instrumentos e dependem de seu fiel cumprimento para que se concretizem as ações tal como planejadas. Tornaria desnecessárias emendas constitucionais, como a recentemente publicada (Emenda Constitucional 86, de 2015), para criar o "orçamento impositivo", e ainda de forma pouco abrangente, restringindo-se aos valores inseridos nos orçamentos pelas emendas parlamentares. ${ }^{8}$

Com efeito, não é mais possível deixar de reconhecer o caráter material da lei orçamentária, ante as inúmeras funções por ela exercidas no âmbito do planejamento, gestão e controle, cujos dispositivos contêm autorizações, proibições e determinações, e vinculam a ação do administrador a perseguir os objetivos e metas, ${ }^{9}$ e afastar, pelo critério da concretude de uma lei orçamentária, o seu controle de constitucionalidade. ${ }^{10}$

Nesse sentido já caminha a jurisprudência, o que é de suma importância para permitir aquele que é um dos mais importantes avanços em curso em matéria orçamentária - o controle de constitucionalidade. Uma evolução que ainda não se completou e é fundamental para dar maior credibilidade e segurança jurídica às leis orçamentárias.

O controle de constitucionalidade das leis orçamentárias, inicialmente não admitido pela nossa Suprema Corte, por reconhecê-la como leis formais, "de efeitos concretos", ${ }^{11}$ passou a ser aceito, com o surgimento das primeiras decisões admitindo a possibilidade de controle de constitucionalidade da lei orçamentária. Cabe destaque à $\mathrm{ADI} 2.925$, que reconheceu "adequado o controle concentrado de constitucionalidade quando a lei orçamentária revela contornos abstratos e autônomos, em abandono ao campo da eficácia concreta”, mas a inflexão mais significativa deu-se na ADI 4.048, já citada no início deste texto, leading case que não deixa mais dúvidas sobre a possibilidade de controle de constitucionalidade das leis orçamentárias, reconhecendo que estas não podem ficar insuscetíveis de controle

8 Sobre a questão do orçamento impositivo, veja as colunas já publicadas no site do Conjur : Orçamento impositivo é avanço para administração em 7 de maio de 2013; Aprovação do orçamento impositivo não dá credibilidade à lei orçamentária em 10 de março de 2015 e Poderes Judiciário e Executivo firmam pacto de combate à corrupção em 25 de março de 2015.

9 FARIA, Rodrigo. Natureza jurídica do orçamento e flexibilidade orçamentária. Dissertação de Mestrado, Faculdade de Direito da USP, 2009.

10 CHRISTOPOULOS, Basile. Controle de constitucionalidade de normas orçamentárias. Tese de Doutorado, Faculdade de Direito da USP, 2014, p. 121.

11 STF, ADI 1640, entre outras. 
judicial, embora ainda não reconheça por completo a possibilidade de amplo controle de conteúdo das normas orçamentárias. ${ }^{12}$

A recente ação (ADPF) movida pelo $\mathrm{PSOL}^{13}$ traz ao debate a tese do "estado inconstitucional de coisas", mostrando que muito ainda se pode esperar em termos de avanço no que tange ao controle de constitucionalidade que envolva matéria financeira. Mas isso é tema que vale uma análise mais detalhada e fica para uma próxima oportunidade.

Enfim, já é hora de deixar no passado a ideia de que a lei orçamentária é uma peça de ficção para colocá-la em seu devido lugar e ocupar merecidamente o espaço que lhe cabe, que é o de lei mais importante depois da Constituição.

12 Nesse sentido, com a análise da evolução da jurisprudência do STF, veja-se CORREIA NETO, Celso de Barros. O orçamento público e o Supremo Tribunal Federal, texto integrante da obra Orçamentos públicos e direito financeiro (CONTI, José Mauricio e SCAFF, Fernando F. (coords.). São Paulo: RT, 2011, p. 111-126). Ainda na mesma obra, vejam-se ASSONI Filho, Sérgio. Controle de constitucionalidade da lei orçamentária, p. 21-40, e NEME, Eliana F. e ARAUJO, Luiz Alberto D. O controle de constitucionalidade de normas orçamentárias, p. 203-214.

13 PSOL pede intervenção do Supremo no sistema carcerário, notícia publicada em 28 de maio de 2015, no site do Conjur. 
